\title{
Reflexões sobre a avaliação de desempenho: uma breve análise do sistema tradicional e das novas propostas
}

\section{Alexandre Shigunov Neto ${ }^{1} \&$ Renata Messias Gomes ${ }^{2}$}

\section{Considerações iniciais}

A avaliação de desempenho tem como principal objetivo diagnosticar e analisar o desempenho individual e grupal dos funcionários, promovendo o crescimento pessoal e profissional, bem como um melhor desempenho.

O presente trabalho teve como objetivos geral realizar uma análise crítica do sistema tradicional de avaliação de desempenho e das novas propostas. Além desse objetivo principal, o trabalho teve como objetivos específicos os seguintes: 1) Analisar as propostas tradicionais e contemporâneas de avaliação de desempenho; 2) Analisar as novas e futuras tendências nos sistemas de avaliação de desempenho; 3) Analisar as posturas necessárias que os administradores, como avaliadores, devem ter diante das mudanças organizacionais e ambientais.

Para alcançar os objetivos inicialmente propostos dividimos o trabalho em 4 partes e a conclusão, assim ordenados: 1) Avaliação de desempenho: seus elementos. Aqui são abordados os elementos que constituem e estão envolvidos direta ou indiretamente nos sistemas de avaliação de desempenho; 2) Sistema tradicional: virtudes, problemas e disfunções. O objeto de estudo desse capítulo é o sistema tradicional de avaliação de desempenho, que vem sendo utilizado a vários séculos pela sociedade e pelas organizações, analisando suas disfunções, problemas e virtudes; 3 ) as mudanças e as novas propostas de avaliação de desempenho. As transformações que ocorrem em todos os níveis também afetam as organizações e os sistemas de avaliação de desempenho. Pretende-se, analisar as principais transformações que influenciam e requerem novas tendências das organizações. Bem como, será realizada uma análise das novas propostas de

\footnotetext{
1 Administrador formado pela Universidade Estadual de Maringá (UEM). Mestre em Educação pelo Programa de Pós-Graduação em Educação da UEM. Coordenador do Curso de Administração da Faculdade Cenecista Presidente Kennedy de Campo Largo-Paraná. Coordenador do Núcleo de Estudos Pedagógicos e Administrativos (NEPA). Email: (shigunov@presidentekennedy.br)

${ }^{2}$ Engenheira Química formada pela Universidade Estadual de Maringá (UEM) e Especialista em Gestão da Qualidade em Alimentos
} 
avaliação de desempenho que começam a surgir e exigem dos profissionais que atuam nas organizações uma nova postura.

\section{Avaliação de desempenho: seus elementos}

A humanidade desde os primórdios adotou a avaliação como um conceito intrínseco aos seus padrões culturais. Pode-se supor que a avaliação sempre esteve presente e ligada ao cotidiano das sociedades, como por exemplo, a escolha de um cônjuge, o presentear um filho por mérito, ou quaisquer gestos de reconhecimento dos indivíduos pelos membros do grupo social ao qual pertencem, no cumprimento de objetivos ou feitos reconhecidos e relevantes segundo o feixe de valores por ele, grupo, construído e defendido.

Juntamente com a evolução da humanidade e dentro dos grupos sociais expandidos observa-se a evolução das organizações de produção, tais processos evolutivos, sempre refletiram, de alguma maneira, as transformações sociais e culturais amplas nos contextos onde estavam inseridas. Conseqüentemente, muito dos conceitos e atitudes vigentes até então sofreram alterações e acompanharam a evolução do sistema capitalista, a avaliação de desempenho não foi exceção.

A avaliação pode ser definida como um instrumento de análise comparativa entre os comportamentos das pessoas, entre uma situação planejada e a ocorrida, entre padrões aceitos e aqueles não aceitos pela sociedade. A avaliação acaba sendo uma técnica de controle humano do sistema capitalista, que acaba sendo encontrado em todos os níveis e setores da sociedade.

A avaliação do desempenho é uma sistemática apreciação do desempenho do indivíduo no cargo e de seu potencial de desenvolvimento. Toda avaliação é um processo para estimar ou julgar o valor, a excelência, as qualidades ou o status de alguma pessoa. (...). A avaliação do desempenho está centrada no ocupante do cargo, isto é, na pessoas.

A avaliação do desempenho constitui uma técnica de direção imprescindível na atividade administrativa. É um meio através do qual se podem localizar problemas de supervisão de pessoal, de integração do empregado à empresa ou ao cargo, do não aproveitamento de empregados com potencial mais elevado que aquele que é exigido pelo cargo, de motivação, etc. De acordo com os tipos gerais de problemas identificados, a avaliação do desempenho pode colaborar na determinação e no desenvolvimento de uma política adequada às necessidades da empresa. (Chiavenato:1981,191-192) 
A importância da avaliação de desempenho refere-se principalmente ao fato de poder diagnosticar, através de inúmeras ferramentas, o desempenho dos recursos humanos da organização em determinado período de tempo. Com a avaliação a organização poderá coletar dados e informações sobre o desempenho de seus funcionários e direcionar suas ações e políticas no sentido de melhorar o desempenho organizacional, por intermédio de programas de melhoria do desempenho individual e grupal dos funcionários.

A avaliação de desempenho possui um estreito relacionamento com as demais funções e setores de Recursos Humanos, sendo esse relacionamento essencial para o funcionamento organizacional.

Um sistema de avaliação de desempenho deve, necessariamente, possuir alguns elementos essenciais para caracterizá-los e atingir seus objetivos. Desse modo, pode-se dividir os elementos de um sistema de avaliação de desempenho em: elementos diretos e indiretos.

\section{Elementos diretos}

Os elementos diretos de um sistema de avaliação de desempenho são aqueles circunscritos na esfera imediata e operacional no processo de obtenção e sistematização de informações, primordiais para a consecução material do sistema.

Os elementos diretos são compostos de: o funcionário avaliado, o avaliador e os instrumentos utilizados, a análise do trabalho executado e o período de tempo avaliado.

\section{O avaliador}

Supõe-se que esse seja o principal elemento do sistema de avaliação de desempenho, pois o resultado final da avaliação dependerá de sua interpretação do diagnóstico realizado e das técnicas utilizadas.

O avaliador poderá ser um funcionário pertencente aos quadros da organização, diretamente envolvido com a instituição, ou um consultor externo, contratado especialmente para realização do trabalho. Cada qual possui suas vantagens e desvantagens, devendo a empresa analisar a situação e escolher aquele que melhor se adequar às suas exigências e necessidades. 
O avaliador externo tem a vantagem de não estar envolvido com a organização e seus membros, dessa maneira, pressupõe-se que realize uma análise objetiva do desempenho dos funcionários. Por outro lado, não pertencendo ao quadro funcional da organização poderá ter sua análise prejudicada ou levar um tempo enorme para concretizar seu trabalho.

Já o avaliador interno tem como principal vantagem conhecer muito bem a organização (seus problemas, suas necessidades, dificuldades, seus potenciais, etc) podendo realizar uma análise criteriosa e minuciosa. No entanto, essa também é sua principal desvantagem, pois está envolvido e comprometido com a instituição e seus membros. Podendo dessa maneira, ser influenciado e realizar uma análise subjetiva do desempenho dos funcionários.

Para a função do avaliador, independentemente de ser interno ou externo, o indivíduo deve ter um conhecimento teórico e prático profundo do sistema adotado para poder obter os dados e informações necessárias a avaliação.

\footnotetext{
Por avaliadores de desempenho entendem-se todas as pessoas que direta ou indiretamente possam estar envolvidas na atividade de detectar diferenças individuais de comportamento em situação de trabalho.

Freqüentemente, considera-se 0 supervisor direto como o único responsável pela avaliação do pessoal na empresa. Essa crença não tem apoio técnico e muito menos científico. Surgiu porque a maioria das empresas que se utilizavam da avaliação faziam do supervisor direto o único participante do processo. Isso aconteceu por muito tempo, sem que essas empresas se apercebessem dos inconvenientes desse tipo de avaliador exclusivo.

A responsabilidade da avaliação se distribui por toda uma equipe de pessoas, que abrange desde o próprio avaliado até aqueles que têm poder de decisão dentro da organização empresarial.

Sejam quais forem os elementos que estejam envolvidos nos procedimentos de avaliação, deve-se antes de tudo ter em mente que são pessoas e, como tal, podem cometer determinados enganos, apesar de sua natural predisposição em desincumbir-se da melhor forma possível dessa responsabilidade que Ihes foi atribuída. É normal e natural que, ao avaliar outra pessoa, uma série de variáveis possam aí interferir, distorcendo o retrato fiel da realidade que se pretende fazer. (Bergamini:1986,143)
}

Falhas estão sujeitas a ocorrer no processo de avaliação, no entanto, podese tentar evitá-los ou minimizá-los com alguns procedimentos, por exemplo: a escolha das técnicas a serem utilizadas, a escolha do grupo de trabalho e seu coordenador, as avariáveis a serem analisadas, etc.

Para realizar a avaliação deve-se primeiramente montar um grupo de trabalho, o tamanho do grupo dependerá principalmente do tamanho da 
organização, pois a avaliação de pessoas é importante e terá influencia direta no desempenho organizacional e uma única pessoa por mais competente que seja não conseguirá realizar um trabalho que alcance os objetivos pretendidos.

\title{
Instrumentos utilizados: elementos de análise
}

$O$ instrumento pode ser definido como sendo o recurso empregado para se alcançar um objetivo determinado, conseguir um resultado esperado.

O método é um programa que regula previamente uma série de operações que se devem realizar, apontando erros evitáveis, em vista de um resultado determinado ou o modo de proceder com vista a atingir um objetivo.

A técnica é o conjunto de processos de uma arte, a habilidade especial de executar algo ou simplesmente a prática.

\begin{abstract}
A avaliação do desempenho pode ser feita por intermédio de métodos que podem variar intensamente não só de uma empresa para outra, mas dentro da mesma empresa, quer trate-se de níveis diferentes de pessoal ou áreas de atividades diversas. Geralmente a sistemática da avaliação do desempenho atende a determinados objetivos traçados com base em uma política de aplicação do pessoal. (...) Cada sistemática atende a determinados objetivos específicos e a determinadas características das várias categorias de pessoas. Há vários métodos de avaliação do desempenho e cada um apresenta vantagens e desvantagens e relativa adequação a determinados tipos de cargos e situações. (Chiavenato:1981,195-196)
\end{abstract}

A escolha do método ou técnicas a serem utilizados no sistema de avaliação influenciará diretamente e decisivamente no resultado final da avaliação. Pode-se classificar o método como sendo a segunda variável mais importante de todo o processo, pois o avaliador terá resultados semelhantes, diferentes ou convergentes em razão da escolha do método. Cabe aos membros do grupo de trabalho formado para executar a avaliação a escolha do método mais apropriado para a organização.

Segundo Bergamini (1986) não há entre os pesquisadores um consenso quanto a classificação atribuída aos instrumentos a serem utilizados nos sistemas de avaliação de desempenho, no entanto, de uma maneira geral pode-se classificálos em 2 categorias: avaliação direta ou absoluta (onde as técnicas utilizadas são centradas no indivíduo avaliado) e a avaliação relativa ou por comparação (com ênfase na eficiência do indivíduo em relação ao seu grupo de trabalho). 
A avaliação de desempenho é um técnica de diagnóstico do desempenho do funcionário em determinado período de tempo, podendo ser utilizados diversos instrumentos e técnicas.

\section{Elementos indiretos}

Os elementos indiretos de um sistema de avaliação de desempenho são aqueles que envolvem aspectos institucionais e valorativos no processo de gestão de negócios. São essenciais ao sistema porquanto dão peso e sentido na interpretação e julgamento das informações coletadas nos elementos diretos de avaliação.

Entre os principais elementos indiretos estão: a organização e suas políticas, a chefia, o grupo de trabalho, os clientes, a recompensa/remuneração e a informação do sistema.

\section{Sistema tradicional: virtudes, problemas e disfunções}

A avaliação de desempenhou acompanhou a evolução das organizações que sempre estiveram de alguma forma refletindo as transformações sociais. Assim, pode-se definir 3 fases do processo de avaliação de desempenho, conforme sua evolução: sistema tradicional; sistema contemporâneo; Propostas futuras

O objeto de estudo dessa parte será o sistema tradicional de avaliação de desempenho, objetiva-se realizar uma análise crítica sobre as virtudes, as disfunções e os problemas conseqüentes do sistema tradicional de avaliação de desempenho utilizado pelas organizações.

\footnotetext{
A avaliação de desempenho visa medir o desempenho do funcionário no exercício do cargo, durante certo período de tempo. Por seu intermédio, a empresa toma conhecimento da conduta do trabalhador, ou seja, se corresponde ou não às expectativas que a empresa teve com relação a ele, por ocasião da seleção oferecendo ao administrador informações sobre as ações do indivíduo no cargo. (Aquino:1980,199)
}

O sistema tradicional de avaliação de desempenho, sendo o instrumento mais utilizado pelas organizações atualmente para avaliarem seus funcionários, 
pode ser classificado como uma técnica de controle e supervisão do trabalho executado pelos funcionários.

\begin{abstract}
A primeira posição é aquela voltada para o passado histórico do empregado na organização, caracterizada pela preocupação em gratificá-lo ou puni-lo por este passado histórico (desempenho). Isto é, uma vez diagnosticada a sua atuação ou desempenho no trabalho, receberá um "prêmio" que se traduzirá em um possível aumento salarial por mérito ou um elogio registrado na sua ficha funcional. Ou então, será "punido" pela privação do aumento e, o que é mais grave, "rotulado" como um empregado deficiente. Como conseqüência, estes 2 resultados condicionarão, profundamente, a construção da história futura do empregado na organização. Caso o empregado tenha sido bem-sucedido na sua avaliação, usufruirá para sempre desta condição, mesmo que seu desempenho real, no futuro, não corresponda mais aquele diagnosticado. Para o empregado malsucedido na avaliação, o melhor seria mudar de emprego, pois seu futuro estará seriamente comprometido pelo julgamento desfavorável que recebeu.

Dentro desta sistemática, a organização e suas chefias não assumem qualquer responsabilidade no processo. Cabe apenas ao empregado arcar, sozinho, com as conseqüências. (Lucena:1977,3-4)
\end{abstract}

O sistema de avaliação de desempenho implantado e utilizado definirá o estilo gerencial e a cultura organizacional subjacente à organização.

Como qualquer processo, o sistema tradicional ${ }^{3}$, por ter sido formulado e adotado por várias décadas sem ter sido revisto e ajustado às transformações ocorridas nesse período foi, e ainda continua, sendo alvo de inúmeras críticas de estudiosos e pesquisadores da área. Entretanto, é preciso sempre analisar criteriosamente essas críticas para verificar se têm validade científica e estão embasadas teoricamente.

As propostas tradicionais de avaliação de desempenho, na maioria dos casos, são utilizados como instrumento punitivo ou de promoção dos funcionários em relação aos resultados esperados pela organização. Isso ocorre porque em muitos casos elas não possuem propostas adequadas de avaliação, técnicas e pessoal qualificado para realizarem a análise, sendo o desempenho dos servidores apenas avaliado pelos superiores. Tornando-se uma avaliação subjetiva e dependente da postura profissional do avaliador, em muitos casos o avaliador utiliza-se do poder como um instrumento punitivo. Mas aos poucos a avaliação de desempenho começa a ser encarada como um instrumento auxiliar no

\footnotetext{
${ }^{3}$ Que vigorou e ainda vigora na maior parte das organizações contemporâneas, como o único instrumento de avaliação dos funcionários, utilizado com o objetivo de quantificar e controlar o desempenho e comportamento individual dos funcionários.
} 
desenvolvimento pessoal e profissional dos funcionários, bem como no desenvolvimento organizacional.

Segundo Milani (1988), os sistemas de avaliação de desempenho são utilizados com múltiplos objetivos, gerando inúmeros problemas e conflitos entre os mesmos. Problemático e conflituoso, pois os objetivos individualmente precisam de estratégias e dados específicos para cumprirem suas funções.

O principal objetivo do sistema tradicional é o de realizar uma análise do desempenho individual dos membros da organização, essa análise leva em conta apenas o trabalho realizado de forma objetiva.

\begin{abstract}
A avaliação deve criar um quadro exato do desempenho de cargo de um indivíduo. Para a realização desta meta, os sistemas de avaliação devem ser relacionados ao cargo, ser práticos, ter padrões e usar medidas confiáveis. Relacionado ao cargo significa que o sistema avalia comportamentos críticos que constituem sucesso no cargo. Se a avaliação não for relacionada ao cargo, é inválida e provavelmente não confiável. Sem validade e confiabilidade, o sistema pode discriminar. Mesmo quando não ocorre discriminação, as avaliações são inexatas e inúteis quando não se relacionam ao cargo. (...) A avaliação de desempenho exige padrões de desempenho. estes são os marcos comparativos para mensuração. Para serem efetivos, devem relacionar-se aos resultados desejados de cada cargo. Não podem ser estabelecidos arbitrariamente. Coleta-se conhecimento destes padrões através da análise de cargo. (Werther:1983,272)
\end{abstract}

Sendo a avaliação de desempenho uma técnica, para atingir seus objetivos faz uso de inúmeros métodos e instrumentos. A definição e escolha dos mesmos ocorre em função das necessidades da organização e dos objetivos propostos.

Os métodos tradicionais de avaliação de desempenho utilizados pelas organizações são classificados de diferentes maneiras pelos pesquisadores, conforme sua conceituação e visão.

Lucena (1977), coloca que a avaliação de desempenho é utilizada como instrumento de desenvolvimento de recursos humanos e classifica em 3 métodos: 1) escolha forçada consiste em avaliar o desempenho dos indivíduos por meio de frases descritivas em relação às tarefas executadas pelo mesmo; 2) pesquisa de campo é o método que avalia o desempenho utilizando-se de entrevista com o chefe; 3) método das escalas gráficas avaliam o desempenho através de uma seqüência de fatores ou qualidades dos indivíduos conforme a graduação 
estabelecida. Para os gerentes, existem 3 métodos que podem ser utilizados: 1) plano analítico de metas; 2) planejamento do trabalho; 3) método da escala gráfica.

Bergamini (1986), classifica os métodos de avaliação de desempenho em 2 grupos. Avaliação direta ou absoluta, são aqueles métodos que fornecem uma quantidade maior de informações sobre o funcionário e a avaliação relativa ou por comparação, são os tipos de avaliação em que a ênfase desloca-se do indivíduo para a eficiência do grupo de trabalho.

o chefe os avalia muito bem;

Apesar de tantos problemas apontados, os métodos tradicionais de avaliação são ainda amplamente utilizados em função de um conjunto de vantagens e virtudes que contém, para uma ampla gama de usuários.

Milani (1988), afirma que as técnicas atualmente utilizadas para avaliação de desempenho dos funcionários das organizações apresentam problemas de ordem funcional, tais como: falta de precisão, confiabilidade, validade de conteúdo e aplicabilidade. Tais problemas inviabilizam a eficiência e a obtenção dos resultados esperados dos métodos utilizados e requerem o desenvolvimento de novas abordagens para avaliação de desempenho.

Como conseqüências das desvantagens apresentadas os sistemas tradicionais apresentam alguns problemas de ordem estrutural e operacional, que afetam proporcionalmente o desempenho organizacional: 1) podem gerar insatisfação e desmotivação nos funcionários; 2) o desempenho organizacional pode ser influenciado negativamente, ficando abaixo do esperado; 3) o ambiente de trabalho pode se tornar instável; 4) podem surgir conflitos entre os funcionários da organização.

Parece que nenhuma técnica para avaliação de desempenho é válida para todas as aplicações. Existem algumas técnicas que contém dados válidos para atingir certos critérios e outras técnicas úteis para atingir outros objetivos. A maioria dos objetivos dos sistemas de avaliação de desempenho requer dados precisos e confiáveis sobre o desempenho atual em termos de realizações esperados e atingidos e comportamentos necessários para atingir os objetivos de uma dada tarefa. Confiabilidade e precisão são mais fáceis de serem atingidas através de eventos observáveis e mensuráveis quando pequena ou nenhuma inferência é permitida. (Milani:1988,53-54) 
Cabe ressaltar que, os sistemas tradicionais de avaliação de desempenho são utilizados par avaliarem o desempenho dos funcionários em determinado período de tempo, ou seja, a análise dos dados coletados é realizada sobre informações passadas, que já ocorreram a algum tempo. Assim, é preciso ter cuidado com a análise e com a utilização dos resultados, pois assim como as organizações os indivíduos e seus comportamentos e desempenhos sofrem transformações e alterações em curto período de tempo. Portanto, as informações coletadas devem servir somente como parâmetros de análise e não como informações absolutas e definitivas sobre o desempenho dos funcionários.

\section{As mudanças e as novas propostas de avaliação de desempenho}

Os sistemas de avaliação de desempenho sempre estiveram presentes no processo evolutivo da humanidade. O ser humano está constantemente sendo avaliado pelos membros da sociedade em que está inserido. Obviamente, este processo toma formas variadas de acordo com sua finalidade e objetivos dos avaliadores.

Nas organizações, é um processo presente e de grande importância para a vida dos funcionários e futuro das organizações. Pode determinar o sucesso ou fracasso pessoal, profissional e organizacional. A razão de ser objeto de estudo pesquisado cada vez mais no âmbito das empresas e da academia, mostra que sem a avaliação de desempenho adequada não há sistema integrado e eficaz de gestão empresarial.

As mudanças em nossa sociedade ocorrem com uma grande velocidade, principalmente na área da Administração, que por ser uma ciência nova seus conhecimentos sofrem transformações e alterações. Assim, essa área de conhecimento transmite aos seus integrantes (pesquisadores e profissionais) a impressão de estarem constantemente obsoletos.

Nas últimas décadas o ser humano provocou e observou inúmeras transformações, de ordem social, econômica, política e cultural. Foi o principal causador e quem sofreu as conseqüências de suas atitudes, seus comportamentos propiciaram tanto benefícios como resultados negativos.

Ao longo dos últimos anos verificamos um processo acelerado de transformações (tecnológicas, culturais, organizacionais, sociais e econômicas), 
rápidas exigindo mudanças culturais e comportamentais das organizações e seus membros. As empresas necessitam descobrir e desenvolver procedimentos que envolvam e comprometam os funcionários com os objetivos organizacionais.

As transformações econômicas, a abertura da economia brasileira ao capital estrangeiro, a formação de blocos econômicos, a estabilização da economia brasileira com o Plano Real, causaram inúmeros problemas e conseqüências para as organizações e seus administradores.

As transformações em nível social e cultural, como por exemplo, o aumento da participação da mulher no mercado de trabalho, a melhoria no nível de escolarização da população, o amplo acesso à informação, geraram novas expectativas e relações dos indivíduos com o trabalho.

As transformações tecnológicas, como 0 surgimento de teorias administrativas - a qualidade. A qualidade como um modelo administrativo atualmente usado pelas organizações deve ser estudada e analisada, pois exerce influência sobre o desempenho organizacional.

As transformações de ordem organizacional são sentidas em diversos níveis, tanto em nível estrutural como operacional. A nível estrutural as organizações precisam tornar mais flexíveis e ágeis para poderem competir no mercado competitivo. A avaliação de desempenho, exerce influência de variáveis externas que atuam sobre as organizações. Essas variáveis podem ser classificadas de diversas formas, por exemplo, os clientes, os fornecedores, o Governo, os concorrentes e demais organizações.

Para Flannery (1997), apesar de cada setor e organização estarem passando por mudanças específicas, existem pelo menos 6 mudanças comuns à todas as organizações: tecnologia em rápida expansão; concorrência global crescente e acirrada; demanda crescente por competências e capacidades individuais e empresariais; maiores expectativas dos clientes; ciclos cada vez mais curtos e mudanças nos requisitos pessoais.

O pensamento administrativo entra em uma nova fase de sua existência, onde conceitos de qualidade, valorização do ser humano, readministração, liderança e estratégias de remuneração começam a ganhar importância no meio empresarial e organizacional. 
As propostas futuras utilizam variáveis novas e outras não tão novas mas que eram analisadas superficialmente como: a qualidade de vida dos funcionários, os aspectos psicológicos envolvidos no processo organizacional, as relações intergrupais, as necessidades dos funcionários, entre outros. Lembrando que a preocupação com os recursos humanos das organizações acentua-se apenas pela impossibilidade das instituições atualmente atingirem plenamente seus objetivos sem que haja o envolvimento e comprometimento de seus funcionários.

\begin{abstract}
Para gerenciar o crescimento do ser humano nas empresas, estamos apresentando e propondo a adoção de um modelo, que denominamos de Tríade para o Gerenciamento, que agrega todos os sistemas de $\mathrm{RH}$ em três segmentos, conforme mostram as figuras 2.1 e 2.3: descobrir a capacidade; utilizar e desenvolver a capacidade e avaliar e retribuir o desempenho. (...) Retornando à Tríade para o Gerenciamento do Crescimento do Ser Humano, existe uma contínua interrelação entre os seus elementos, e o desejável seria a existência de uma dinâmica crescente entre eles, de tal forma que o aumento da capacidade implique na sua maior e melhor utilização, que por sua vez permita a melhor avaliação e maior retribuição do desempenho. (Böhmerwald:1996,9)
\end{abstract}

Alguns conceitos muito difundidos e divulgados atualmente são novos, como a readministração e estratégias de remuneração, enquanto que outros, como a liderança, a qualidade e a valorização do ser humano apenas ganharam uma nova roupagem.

A tendência humana em buscar em conceitos formulados no passado não é nova, e também não é de exclusividade da Administração. Em todas as áreas de conhecimento e ciências verifica-se essa procura incessante e incansável de desvendar o desconhecido com o auxílio de conceitos formulados no passado por grandes cientistas e pesquisadores.

Com as mudanças organizacionais verificadas atualmente começam a surgir propostas alternativas e a qualidade é tida como um instrumento auxiliar para os administradores tornarem as organizações eficientes e competitivas, levando em conta as necessidades dos seus funcionários.

Segundo o Dicionário Aurélio, qualidade é o atributo ou condição das coisas ou pessoas capaz de distingui-las das outras e de lhes determinar a natureza. Numa escala de valores, a qualidade permite avaliar e, conseqüentemente, aprovar, aceitar ou recusar, qualquer coisa. É disposição moral ou intelectual das pessoas. Dote, dom, virtude. É a condição, posição, função. Uma das categorias 
fundamentais do pensamento: maneira de ser que se afirma ou se nega uma coisa. Aspecto sensível, e que não pode ser medido, das coisas. Assim, apesar da evolução do conceito e das inúmeras definições que surgiram no decorrer do tempo, os princípios pregados na atualidade mantém suas origens.

A concepção que funciona como fio condutor e integrador das categorias por nós eleitas parte da idéia de que as organizações têm um caráter instrumental, que sua função precípua é atender e satisfazer as necessidades de uma clientela específica e que, para desempenhar suas funções, necessitam: de objetivos claros, para não perder seu rumo; de recursos humanos competentes e motivados para materializar tais objetivos; de informações precisas e que circulem, pois estas estão para a organização como o sangue par ao corpo humano; de políticas que funcionem como parâmetros facilitadores da consecução dos objetivos; de estratégias de que determinem o como operar para viabilizá-los (operar com a noção de futuro, pois todas as organizações funcionam em certo ambiente temporal e devem balancear as noções de curto, médio e longo prazos); de uma noção sistêmica, que permita que elas sejam gerenciadas a partir de uma ótica mais globalista, evitando que as concepções das unidades isoladas prevaleçam sobre a visão do todo; e finalmente, de uma estrutura, que é a roupagem final mais adequada - e possível - de que se reveste a organização para garantir a consecução dos seus objetivos. (Caravantes:1997,11)

Qualidade é um padrão de desempenho subjetivo, pois os indivíduos adquirem produtos e/ou serviços para tentarem satisfazer necessidades conscientes e/ou inconscientes com a percepção que têm do objeto de cobiça.

A qualidade, como a maioria dos conceitos aplicados e formulados na Administração, passou por diversas fases de evolução.

Shiba (1997), coloca que a qualidade pode ser considera sob diversos prismas, difíceis de serem definidos. A evolução do TQM é descrita com a explicação de alguns de seus conceitos básicos, descreve os 4 níveis de qualidade, com seus pontos fracos: 1) adequação ao padrão - avalia se o produto produzido está adequado aos padrões estabelecidos; 2) adequação ao uso - é o meio de garantir a satisfação das necessidades de mercado; 3) adequação ao custo significa alta qualidade e custo baixo; 4) adequação à necessidade latente significa a satisfação das necessidades do cliente antes que eles estejam conscientes delas.

A qualidade tornou-se nos dias atuais o centro das atenções de todos administradores e especialistas, sendo um dos principais objetivos a ser perseguido pelas organizações. Além de ser considerada de grande importância é fator 
primordial de sobrevivência e destaque daquelas que pretendem conquistas seu lugar no competitivo mercado. O tema da qualidade e as discussões sobre ela são inúmeras, todos conseguem de algum modo defini-la e de sua importância para as organizações, mas a grande dificuldade é colocá-la em prática. Para que a organização atinja a qualidade total é necessário que haja primeiramente o envolvimento e comprometimento da alta administração, pois a implantação de tal programa envolve e modifica a cultura organização e o comportamento dos funcionários.

A qualidade foi inicialmente concebida como um conceito, essencialmente, tecnicismo e embasada nos princípios de racionalidade do trabalho, zero defeitos, fim do retrabalho e satisfação do cliente, conforme visto no conceito apresentado no capítulo IV por Shiba (1997). Entretanto, a qualidade entra em uma nova fase de sua evolução, a também valorizar e dar ênfase a princípios humanísticos, tais como: qualidade de vida no trabalho, treinamento e desenvolvimento de pessoal e satisfação e bem-estar dos funcionários.

Embora a qualidade de vida no trabalho tenha voltado a ser uma preocupação dos gerentes durante o início da década de 1980, ainda há alguma incerteza quanto ao seu significado exato. Em um nível, defende-se que a QVT não passa de uma definição elaborada de desenvolvimento organizacional. Outros, entretanto, argumentam que a QVT é muito mais ampla e diversificada que os esforços de DO, e que é mais característica de um processo que envolva toda a organização.

A literatura traça a QVT essencialmente em 2 dimensões amplas. Um conjunto de definições equaciona a QVT com a existência de um certo conjunto de condições e práticas organizacionais tais como cargos enriquecidos, participação dos empregados nos processos de tomada de decisões, condições seguras de trabalho e assim por diante. Uma outra abordagem equaciona a QVT com os efeitos visíveis que as condições de trabalho têm no bem-estar de um indivíduo (por exemplo, manifestações de satisfação no local de trabalho, crescimento e desenvolvimento dos funcionários, a capacidade de atender a todas a gama de necessidades humanas). As diferenças entre esses 2 conjuntos de definições, na maioria dos casos, é mínima visto que as condições e características do trabalho relacionadas a uma "boa" qualidade de vida no trabalho geralmente têm efeitos positivos na satisfação e na percepção dos empregados. A segunda orientação, entretanto, admite que nem todas as pessoas podem perceber intervenções, do tipo cargos enriquecidos, como componentes importantes de uma "boa" qualidade de vida no trabalho. A despeito do conjunto de definições adotado, os elementos que distinguem as questões da QVT são: 1) preocupação com o efeito do trabalho nas pessoas bem como na eficácia da organização; e 2) a idéia da participação dos trabalhadores na solução de problemas e tomada de decisões da organização. (Bowditch \& Buono:1992,206-207) 
Essa preocupação com os recursos humanos da organização pode ser visualizado também no Plano ${ }^{4}$ Nacional de Qualidade (PNQ) que ao definir seus critérios para certificação das organizações relaciona vários quesitos ligados as áreas de recursos humanos, mais especificamente de desempenho humano, sendo que a participação proporcional da importância da avaliação do fator humano, vem aumentando a cada nova edição dos quesitos de avaliação do referido Prêmio. Neste sentido a avaliação de desempenho representa uma variável administrativa de central e cada vez mais imprescindível importância, como instrumento de gestão eficaz das organizações, justificando a multiplicação de estudos na área.

A valorização do ser humano é uma tendência que volta a ser discutida e empregada no pensamento administrativo. Essa tendência humanística está embasada em princípios que se preocupam e consideram aspectos motivacionais, psicológicos e comportamentais dos indivíduos.

Vroom (1997), afirma que conquistar a satisfação dos funcionários através da concessão de recompensas não é tão fácil quanto parecer, pois depende de vários fatores: 1) a satisfação do indivíduo com as recompensas está relacionada à expectativa e à quantia recebida; 2) a satisfação do funcionário depende da comparação com outros funcionários que ocupam cargos idênticos; 3) os funcionários não conseguem compreender a recompensa recebida pelos colegas de trabalho, geando insatisfação; 4) a satisfação, normalmente, resulta de um conjunto de recompensas.

O homem é um ser que possui necessidades, desejos e sentimentos que precisam ser considerados e analisados, pois influenciam o comportamento e o desempenho dos funcionários da organização. Essa valorização justifica-se pela compreensão, por parte dos administradores, de que as pessoas são o maior e mais importante recurso disponível da organização. Somente com a cooperação e contribuição de todos os membros organizacionais é que será possível, numa época de grandes transformações e exigências, atingir os objetivos propostos e alcançar

\footnotetext{
${ }^{4}$ O Prêmio nacional da Qualidade (PNQ) é uma premiação que ocorre anualmente, premiando organizações brasileiras que se destacaram na gestão da qualidade. O PNQ adota desde sua criação os critérios do Prêmio Americano, Malcom Baldrige National Quality Award. A metodologia utilizada baseia-se, essencialmente, em categorizar 7 variáveis organizacionais e atribuir uma pontuação máxima a eles: 1) liderança (90 pontos); 2) informação e análise (75 pontos); 3) planejamento estratégico (55 pontos); 4) desenvolvimento e gestão de recursos humanos (140 pontos); 5) gestão
} 
índices cada vez maiores de satisfação, tanto dos membros organizacional como dos clientes. É preciso compreender que o funcionário para produzir o desempenho esperado e ter uma evolução profissional e conseqüentemente em seu desempenho precisa estar satisfeito com o trabalho realizado e com sua organização.

\begin{abstract}
É hora dos líderes das empresas começarem a pensar com maior seriedade sobre os conceitos de liderança e organização. Precisam fazê-lo em nome de suas próprias organizações, bem como da sociedade. A questão que discuti é de importância crítica para a sociedade como um todo, pois a sociedade, cada vez mais, é composta de organizações. Quanto menos efetivamente as organizações realizarem o trabalho da sociedade, maior será o curso, em termos de capital e de paralisia social. Essa última leva ao tipo de desmoralização que já está evidente nas organizações, bem como a problemas de transporte, assistência médica, entrega, educação e bem-estar.

Além disso, estamos em meio a uma revolução social mundial, cujo impulso central é a exigência das pessoas do direito de influenciar seu destino. Os líderes das empresas, muitos dos quais têm interesses internacionais e vêem as múltiplas facetas desse impulso em uma ampla gama de países, devem estar à frente da compreensão e direcionamento dessas mudanças sociais para canais produtivos. Aplicando novos princípios de motivação a suas próprias organizações, eles estão em posição não só de sustentar a vitalidade dessas organizações como também, o que é mais importante, de mantê-las adaptavas às circunstâncias mutáveis. (...)

Liderar, porém, é mais do que uma questão de pronunciar cliclês. Envolve uma compreensão da motivação. É a essa compreensão a que os líderes das empresas devem se dedicar agora. E, para começar, devem combater a grande falácia dos tolos em suas próprias organizações. (Vroom:1997,93)
\end{abstract}

O papel do funcionário nessas novas propostas de avaliação de desempenho tem um mudança radical em comparação com o sistema tradicional, passando da função passiva e de mero espectador do processo para assumir mais responsabilidades e a função de agente ativo. De acordo com Vroom (1997) a abordagem de avaliação de desempenho adotado pela organização deve atribuir ao funcionário maior responsabilidade na definição de metas e pela avaliação do desempenho, pois assim, evitaria as principais desvantagens dos sistemas tradicionais e estimularia o desenvolvimento dos recursos humanos, afirma ainda que, a motivação e o desenvolvimento dos subordinados geram custos que podem facilmente recuperáveis com os benefícios alcançados.

de processos (140 pontos); 6) resultados do negócio (250 pontos); 7) focalização no cliente e sua satisfação (250 pontos). 
Segundo pensamento contemporâneo, o processo "ideal" deve evoluir em 5 etapas: 1) discussão individual com o superior da descrição feita pelo subordinado de seu próprio cargo, 2) fixação de metas de desempenho a curto prazo, 3) reuniões com o superior para discutir o progresso em direção às metas, 4) definição de pontos de verificação para avaliar o progresso e 5) discussão entre superior e subordinado ao final de um período definido para avaliar os resultados dos esforços do subordinado. $\mathrm{Na}$ prática ideal, esse processo ocorre contra um pano de fundo de contatos e freqüentes até mesmo diários, e independente da análise salarial. (Vroom:1997,206-207)

$\mathrm{O}$ investimento no ambiente de trabalho e $\mathrm{n}$ indivíduo torna-se fator primordial para o desenvolvimento organizacional, somente assim, a organização poderá conquistar e manter por longo prazo seu espaço no competitivo mercado. Faz-se necessário compreender que o investimento nos recursos humanos e ambiente organizacional são insignificantes em relação ao retorno que poderão ser conseguidos, ou seja, não se pode entender o gasto com os funcionários como um custo e sim como um investimento altamente lucrativo.

As organizações, visando obter comprometimento, cooperação e envolvimento dos funcionários e conseqüentemente um melhor desempenho, começam a investir em estratégias de remuneração diversificadas. Pois, compreenderam que para o funcionário estar envolvido e comprometido com os objetivos organizacionais deve estar, primeiramente, motivado e satisfeito com sua instituição.

Existem inúmeras maneira de fazer com que haja um envolvimento e comprometimento dos funcionários, que vão desde a adoção de estratégias de remuneração até uma verdadeira preocupação com o ambiente de trabalho e com o funcionário enquanto ser humano, que possui sentimentos, desejos e necessidades. Uma das alternativas encontradas por algumas empresas, principalmente, multinacionais, é a remuneração por desempenho, sendo o funcionário remunerado pelo desempenho apresentado. Surgi aqui uma indagação: será que essas organizações possuem um sistema coerente e eficaz de avaliação de desempenho dos seus funcionários?

As organizações contemporâneas, com visão de futuro, compreenderam o papel fundamental dos recursos humanos no desenvolvimento organizacional, e começaram a procurar adotar estratégias voltadas a valorização de seus funcionários e a gratificá-los pelo desempenho. Desse modo, a implantação e 
adoção de uma política de recursos humanos, coerente e preocupada em proporcionar condições de desenvolvimento pessoal e profissional dos funcionários, que direcional e organize as propostas de gestão de recursos humanos da organização é fator condicionante para atingir seus objetivos.

Conforme Flannery (1997), os programas de benefícios oferecidos pelas organizações têm um papel cada vez mais importante, seus custos são elevados, no entanto, os serviços oferecidos evoluíram nos últimos anos. E apresenta alguns programas tradicionais e inovações, baseadas em mudanças de desejos, necessidades e valores e voltadas, principalmente, para a família dos funcionários, utilizadas atualmente: 1) assistência médica; 2) benefícios de aposentadoria; 3) seguro de vida e planos de invalidez; 4) política de férias e feriados; 5) programa de assistência ao empregado; 6) assistência infantil; 7) horário flexível; 8) dias para assistência a dependentes; 9) política de trabalho domiciliar; 10) despesas com adoção; 11) assistência de longo prazo.

As novas propostas de avaliação de desempenho utilizam-se de estratégias de remuneração diversificadas como instrumento motivacional de seus funcionários, adotando muitas vezes um conjunto de remunerações e não apenas um modelo.

A Readministração é um conceito recente que utiliza-se dos princípios da qualidade e reengenharia, dando ênfase aos recursos humanos da organização e sua otimização.

Conforme Caravantes (1997), a Readministração é estruturada sobre a teoria e a prática administrativa, destacando elementos, supostamente, necessários para um novo tipo de gerência capaz de conduzir as organizações para a próxima década. Entre os principais elementos estão: 1) necessidade de compreensão da organização e seus ambiente externo; 2) importância do estabelecimento de objetivos e missão da organização; 3) compreensão dos fatores que afetam o comportamento e desenvolvimento dos recursos humanos; 4) administração de recursos físicos e financeiros; 5) e obtenção de resultados socialmente relevantes.

Por outro lado, se há algo que os autores têm plena consciência é o fato de que nem as organizações - verdadeiras ficções legais - nem as novas teorias ou tecnologias organizacionais - abstrações mentais - são capazes de, por si só, causarem alguma modificação substancial no contexto em que vivemos. As mudanças necessárias, de que falamos e que almejamos com certa ansiedade, decorrem, a nosso ver, da ação de indivíduos, especialmente daqueles colocados em posição-chave nas organizações. 
São indivíduos que tomam decisões, que afetam 0 destino das organizações por eles dirigidas; são os que chamamos de Executivos ou Administradores. Sem eles as novas teorias permaneceriam inertes, meras propostas sem vida.

Por outro lado, a postura do Executivo ou do Administrador, sua forma de agir no dia-a-dia organizacional, decorre necessariamente de sua visão de mundo, suas concepções, percepções e valores - que às vezes não estão suficientemente claros nem para o próprio executivo. $O$ que os autores desejam é repartir com os leitores uma visão passível, e a seu ver desejável, a visão existencialista, e seu impacto nos resultados organizacionais.

A Readministração, com sua proposta de garantir organizações de alto desempenho (eficientes, eficazes e efetivas) e indivíduos felizes/autoatualizados, necessita, a nosso ver, de executivos capazes de refletirem substancialmente e de agirem pragmaticamente. (Caravantes:1997,192)

O termo Readministração foi por nós utilizado como sendo uma nova visão e postura do que seja administração e gerência nos tempos atuais e futuros, assim, o termo foi utilizado por aproximar do conceito do que deva ser o novo modelo de gerência. $O$ princípio que deve nortear esse novo modelo de gerência para as organizações é aquele em que os indivíduos organizacionais são o principal fator propulsor e impulsionador da organização.

O conceito de liderança é antigo e está ligado ao de organizações e à evolução da humanidade. Ao longo dos séculos surgiram pessoas que se destacaram e gravaram seus nomes na história da humanidade por terem a capacidade de incitarem e coordenarem movimentos sociais de desagrado e insatisfação com situações vigentes, causadas normalmente pelo autoritarismo e abuso de poder dos governantes.

As exigências sociais e organizacionais, comparativamente, a alguns anos têm tido um crescimento além do esperado, exigindo dos administradores novos conhecimentos, percepções, aptidões e principalmente uma capacidade denominada de liderança.

Paradigmas existentes sobre o papel da autoridade, o poder e mesmo sobre a pessoa e função dos líderes devem ser quebrados e ultrapassados.

A gerência é a arte de pensar, de decidir e de agir; é a arte de fazer acontecer, de obter resultados. Resultados que podem ser definidos, previstos, analisados e avaliados, mas que têm de ser alcançados através das pessoas e numa interação humana constante.

De um lado, pode-se tratar a gerência como algo científico, racional, enfatizando as análises e as relações de causa e efeito, para se prever e antecipar ações de forma mais conseqüente e eficiente. De outro, tem-se de aceitar a existência, na gestão, de uma face de imprevisibilidade e de 
interação humana que lhe conferem a dimensão do ilógico, do intuitivo, do emocional e espontâneo e do irracional. Dirigentes devem entender a gestão moderna em ambos os sentidos. A formação no lado racional e técnico da gerência permite dar aos indivíduos uma grande capacidade analítica. (...)

O vício no pensamento excessivamente técnico, restrito a uma área ou profissão pode ser uma desvantagem para o exercício da função gerencial. A visão extremamente técnica é análoga a uma visão através de um túnel: vê-se a luz ou ambiente ao final, porém restrita à dimensão do diâmetro desse túnel. Na profissão, vê-se somente um caminho obscurecido pela impenetrabilidade dos raios de outros conhecimentos.

A arte de pensar e julgar que caracteriza a gerência exige maios amplitude e lateralidade de pensamento. Por isso é recomendado aos dirigentes que adquiram conhecimentos ou mesmo formação avançada para estimular a sua mente e curiosidade, na busca de novos horizontes e perspectivas sobre a realidade em que estão inseridos. Assim, o aprendizado sobre a gestão para formar dirigentes e líderes também não deve se limitar ao domínio de técnicas administrativas. Estas técnicas servem apenas para melhorar as estruturas e procedimentos organizacionais. Melhorar o que existe é importante, mas aprender coisas novas é crucial para sobrevivência e relevância. (Motta:1996,26-27)

\section{As atuais futuras exigências organizacionais exigem dos profissionais que} atuam na estrutura organizacional novas posturas e principalmente, uma nova formação profissional, pautada em princípios humanísticos e generalistas. Esse profissional deverá, necessariamente, estar em constante aperfeiçoamento e preocupado com sua formação.

Liderar significa descobrir o poder que existe nas pessoas, torná-las capazes de criatividade, auto-realização e visualização de um futuro melhor para si próprios e para a organização em que trabalham. Para isso o líder tem de descobrir em si mesmo o poder de vislumbrar um novo futuro, e novas alternativas dentro do papel gerencial e da missão que lhe é conferida. A visão clara da missão e das alternativas e a habilidade de comunicá-las com exatidão servem como atrativo e fonte de confiança para os subordinados (liderados) que participam do empreendimento coletivo.

Assim, a liderança requer habilidades individuais, de autoconhecimento, de expressão e de comunicação. bem como capacidade de enfrentar o futuro com confiança, ousadia e flexibilidade. Exige habilidades interpessoais de tratar com grupos e indivíduos, transferindo-lhes poder e iniciativa para que descubram a si próprios e encontrem os melhores caminhos para autorealização e desempenho de suas tarefas. Ademais, a liderança requer conhecimento da organização e do ambiente ao seu redor, para melhor conhecer a missão que tem de desempenhar em função do público a que serve.

Enfim, liderança nada tem de mágica, de mistério, nem de propriedade de pessoas eminentes ou de indivíduos possuidores de qualidades especiais inatas. A liderança é essencialmente o resultado de habilidades humanas aprendidas por pessoas comuns e, portanto, perfeitamente tratáveis como uma dimensão básica da formação gerencial. Liderança não é uma condição passiva, mas produto de participação, envolvimento, comunicação, cooperação, negociação, iniciativa e responsabilidade. (Motta:1996,221) 
Os profissionais que ocuparem cargos de chefia nas organizações, necessariamente, deverão possuir a capacidade de liderança. Pois, somente assim poderão gerenciar os recursos humanos disponíveis de forma eficiente e eficaz. A capacidade de liderança é necessária e imprescindível para a organização, pelo fato desta ser inconstante e ser alvo de inúmeros conflitos.

Nas organizações futuras encontraremos uma nova e bem estrutura organização. Organizações ágeis e flexíveis para enfrentarem as exigências e necessidades do mercado; chefes com uma visão mais ampla e com a função de orientação de seus subordinados; funcionários satisfeitos, comprometidos e envolvidos com suas funções e responsabilidades dentro da estrutura organizacional.

Em síntese, as novas propostas tendem para abordagens humanísticas, levando em consideração o homem e seus fatores psicológicos. Mesmo as novas propostas de avaliação de desempenho possuem problemas e disfunções, que devem ser levados em consideração pela organização e seus administradores. Provavelmente, a melhor solução para minimizar tais disfunções e problemas seja a adoção de dois ou mais instrumentos, que devem estar em consonância com os objetivos organizacionais.

\section{Considerações finais}

A avaliação de desempenho enquanto uma técnica de diagnóstico e análise do desempenho individual e grupal dos membros da organização, deve ter como objetivo geral e principal promover o desenvolvimento pessoal e profissional dos indivíduos, bem como uma maior produtividade e melhor desempenho organizacional.

A avaliação de desempenho acompanhou a evolução do pensamento administrativo e apropriou-se dos princípios adotados pelas abordagens administrativas para atingir seus objetivos previamente propostos. $O$ foco de abordagem de um processo de avaliação de desempenho é a relação existente entre contribuição $X$ retribuição. $O$ que verifica-se é que, dependendo da época $e$ do sistema de avaliação utilizado, a relação sofrerá alterações. 
No sistema tradicional a variável principal é a contribuição que o funcionário pode proporcionar, sendo a retribuição o "minimum" socialmente estabelecido para que o funcionário sobreviva enquanto trabalha e seja capaz de gerar um substituto quando findar tal capacidade de trabalho como modelo vigente desde os primórdios do sistema capitalista de produção. Além disso, a retribuição do trabalho só se dava em termos monetários como fica claro no conceito taylorista de "homem econômico", isto é, exclusivamente remuneração direta e segundo os critérios de estrita racionalidade econômica de reprodução do capital. Já no sistema atual começa a haver uma preocupação em encontrar-se um equilíbrio, enquanto que as tendências futuras tendem a buscar uma harmonia perfeita entre as variáveis envolvidas no processo e que possam influenciar o comportamento e desempenho do funcionário.

No confronto entre virtudes de problemas dos métodos tradicionais de avaliação, podemos constatar um conjunto maior de desvantagens do que benefícios, em função do quadro atual de exigências nas relações de trabalho. Os funcionários dificilmente, ou com muita resistência, aceitam sistemas de avaliação que estão pautados por certas características, tais como: os sistemas tradicionais são métodos subjetivos e incompletos, as avaliações são realizadas, normalmente, pelos chefes imediatos, não levam em consideração variáveis psicológicas e comportamentais dos indivíduos, os itens analisados pelos sistemas são escolhidos aleatoriamente pelo avaliador, não levam em consideração as condições do ambiente de trabalho, podem ser geradores de conflito e discórdia entre os membros da organização, são métodos utilizados, em geral, da mesma forma para todos os cargos e funções da organização, são métodos comparativos e discriminativos e realizam o diagnóstico e análise sobre acontecimentos, comportamentos e desempenho passados.

Como principais vantagens, apresenta as seguintes: baixo custo, geralmente, para sua elaboração e aplicação, as informações necessárias para realização da avaliação são obtidas facilmente, podem ser realizadas rapidamente, na maioria dos casos, são de fácil aplicação e elaboração, e, normalmente, são métodos simples. Os sistemas tradicionais apresentam alguns problemas de ordem estrutural e operacional, que afetam proporcionalmente o comportamento e desempenho individual e organizacional: podem gerar insatisfação e desmotivação nos funcionários, o desempenho organizacional pode ser influenciado negativamente, 
ficando abaixo do esperado, o ambiente de trabalho pode se tornar instável e podem surgir conflitos entre os membros da organização.

Com as transformações econômicas, sociais, culturais, políticas, tecnológicas também as organizações estão mudando com grande velocidade. Essas mudanças tiveram como conseqüência para as organizações uma maior competitividade e um aumento das exigências dos consumidores. Essas transformações também exigiram e exigem das organizações mudanças de paradigmas e uma reflexão sobre os modelos e técnicas administrativas adotadas. Dessa maneira, as organizações começam a se preocupar com os seus recursos humanos, preocupação essa voltada para o ambiente de trabalho adequado, segurança e higiene no trabalho e o crescimento pessoal e profissional do funcionário.

As organizações são hoje mais sensíveis às demandas dessa natureza, percebendo que só assim poderão motivar seus funcionários a atingirem os objetivos organizacionais.

Podemos, dessa maneira, intuir que a Administração nos anos vindouros seguirá uma tendência humanística e exigirá dos profissionais que atuam nas organizações, novas posturas e também uma formação profissional sólida e coerente. O papel que caberá aos sistemas de avaliação de desempenho nessa nova fase da Administração é essencial para contribuir com o crescimento pessoal e profissional dos indivíduos, sendo um instrumento auxiliar no desenvolvimento da organização e satisfação daquelas que a ela pertencem.

\section{BIBLIOGRAFIA}

AQUINO, Cléber Pinheiro de. Administração de recursos humanos: uma introdução. São Paulo: Atlas, 1980.

BERGAMINI, Cecília Whitaker. Avaliação de desempenho humano na empresa. 3를 edição. São Paulo: Atlas, 1986.

BOWDITCH, James L. \& BUONO, Anthony F. Elementos de comportamento organizacional. São Paulo: Pioneira, 1992.

BÖHMERWALD, Pedro. Gerenciando o sistema de avaliação de desempenho. Belo Horizonte: UFMG: Fundação Christiano Ottoni, 1996. 
CARAVANTES, Geraldo R. Administração e qualidade: a superação dos desafios. São Paulo: Makron Books, 1997.

CHIAVENATO, Idalberto. Administração de recursos humanos. $2^{\underline{a}}$ edição. São Paulo: Atlas, 1981.

FLANNERY, Thomas P. Pessoas, desempenho e salários: as mudanças na forma de remuneração nas empresas. São Paulo: Futura, 1997.

FUNDAÇÃO PARA O PRÊMICO NACIONAL DA QUALIDADE (PNQ. Critérios de excelência: o estado da arte da Gestão da Qualidade Total. São Paulo: 1995.

LUCENA, Maria Diva da Salete. Avaliação de desempenho: métodos e acompanhamento. São Paulo: McGraw-Hill do Brasil, 1977.

MILANI, lone. Sistemas de avaliação de desempenho: uma revisão de literatura. Revista de Administração: Editora da USP. Vol. 23 (3), jul/set/1988. P. 45-57.

MOTTA, Paulo Roberto. Gestão contemporânea: a ciência e a arte de ser dirigente. $7^{\mathrm{a}}$ edição. Rio de Janeiro: Record, 1996.

SHIBA, Shoji. TQM: quatro revoluções na gestão da qualidade. Porto Alegre: Artes Médicas, 1997.

WERTHER, William B. Administração de pessoal e recursos humanos. São Paulo: McGraw-Hill do Brasil, 1983.

VROOM, Victor H. Gestão de pessoas, não de pessoal. Rio de Janeiro: Campus, 1997. 